\title{
A Multidisciplinary Review of Recycling Methods for End-of-Life Wind Turbine Blades
}

\author{
Ebbe Bagge Paulsen ${ }^{1}$ and Peter Enevoldsen ${ }^{2, *}$ \\ 1 Siemens Gamesa Renewable Energy, Borupvej 16, 7330 Brande, Denmark; ebbe.paulsen@siemensgamesa.com \\ 2 Center for Energy Technologies, Department of Business Development and Technology, Aarhus University, \\ BTECH Aarhus BSS Aarhus University, Birk Centerpark 15, 7400 Herning, Denmark \\ * Correspondence: peterenevoldsen@btech.au.dk
}

Citation: Paulsen, E.B.; Enevoldsen, P. A Multidisciplinary Review of Recycling Methods for End-of-Life Wind Turbine Blades. Energies 2021 14, 4247. https://doi.org10.3390// en14144247

Academic Editor: Felix A. Lopez

Received: 10 June 2021

Accepted: 9 July 2021

Published: 14 July 2021

Publisher's Note: MDPI stays neutral with regard to jurisdictional claims in published maps and institutional affiliations.

Copyright: (c) 2021 by the authors. Licensee MDPI, Basel, Switzerland. This article is an open access article distributed under the terms and conditions of the Creative Commons Attribution (CC BY) license (https:// creativecommons.org/licenses/by/ $4.0 /)$

\begin{abstract}
Wind energy has seen an increase of almost $500 \mathrm{GW}$ of installed wind power over the past decade. Renewable energy technologies have, over the years, been striving to develop in relation to capacity and size and, simultaneously, though with less focus on, the consequences and challenges that arise when the products achieve end-of-life (EoL). The lack of knowledge and possibilities for the recycling of fiber composites and, thus, the handling of EoL wind turbine blades (WTBs) has created great environmental frustrations. At present, the frustrations surrounding the handling are based on the fact that the most commonly used disposal method is via landfills. No recycling or energy/material recovery is achieved here, making it the least advantageous solution seen from the European Waste Commission's perspective. The purpose of this research was thus to investigate the current recycling methods and to categorize them based on the waste materials. The opportunities were compared based on processing capacity, price, environment and technology readiness level (TRL), which concluded that recycling through co-processing in the cement industry is the only economical option at present that, at the same time, has the capabilities to handle large amounts of waste materials.
\end{abstract}

Keywords: wind power; recycling; blades; end-of-life

\section{Introduction}

Reviewing the European energy market, the wind industry is ranked as the fastest growing energy source with an increase of 15.4 GW in 2019 [1]. This places wind energy in second place over the highest cumulative energy sources in the EU, ranked just after natural gas [2]. Since 2008, more than $140 \mathrm{GW}$ of wind capacity has been installed in the EU, corresponding to a total capacity of 205 GW in 2018, covering 15\% of European electricity consumption [3]. Based on WindEurope's mid-term wind energy market outlook analysis, it is estimated that the total cumulative European capacity in 2023 will have increased to between 254 and 299 GW of wind energy [4].

Wind turbines have become the symbol of the renewable transition [5]. This is also supported by wind turbine life cycle assessments (LCA), which describe the environmental impact of the product throughout its lifetime. Here, studies show that wind turbines repay between 23 and 57 times the energy it takes to produce the turbine over its entire lifetime [6]; however, the estimated valuation of total environmental losses still range from EUR 500,000 to EUR 1.1 million per wind turbine considering both on- and offshore wind turbines [7]. Current wind turbines will have a recyclability at around $86 \%$, which is mainly due to the high content of steel for which commercial recycling methods exist [8]. Based on an assessment described by [9], the individual components are described in relation to uncertainty on how they should be recycled and the importance of finding a solution. The study found that blades constitute a major problem, and there is much uncertainty about how to dispose/recycle them properly and safely. Even though the research was published back in 2014-2016, there is still not established a commercial and 
environmental solution $[9,10]$. This is further emphasized in the statement from Vestas, namely that, "on the road to achieving a 100 percent recyclability, the composite materials of the blades comprise the largest component yet to be made recyclable" $[9,11,12]$. This research therefore investigates the problem of handling end-of-life (EoL) blades and mainly looks at the problem of the composite parts, due to the fact that a standard wind turbine blade consists of $90 \mathrm{wt} \%$ composite material and the rest of the content is a mixture of PVC, balsa wood, metal, paint and sealing. According to various studies [13-15] the general composition of a blade is:

composite material $\sim 93 \%$

PVC $2 \%$

balsa wood $\sim 2 \%$

metal, paint and putty $\sim 3 \%$

Some of the first wind turbine blades were designed from the National Advisory Committee for Aeronautics (NACA) profiles, which, over time, have been optimized, and there are now many different profile types used by individual manufacturers [16]. Although many different manufacturers exist, most WTBs are constructed more or less alike. A typical structure is seen in Figure 1, in which the blades consist of three main parts: two aerodynamic shells (on the compression side and the tension side), which are joined together and stiffened by either one or several integral (shear) webs or by a box beam $[14,17]$.

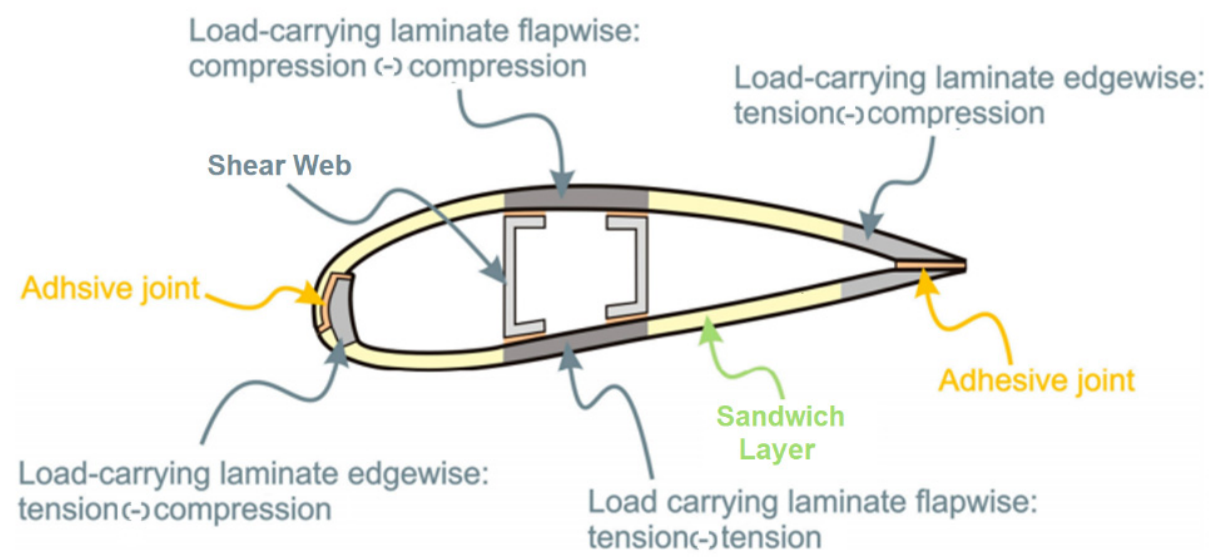

Figure 1. WTB schematic cross-section and structure, inspired by [14].

At present, most of the blades consist of polymer composite reinforced with glass fibers (GF); some are reinforced with carbon fibers (CF), and more and more hybrid combinations of glass fibers and carbon fibers are being introduced. The resin is most often high-grade epoxy or polyester. In addition to the composite materials being virtually impossible to separate to enable recycling due to the cross-linking that occurs between resin and fibers during curing, the glass fiber materials are considered to be a low value material, which makes the incentives for recycling even less attractive $[18,19]$. The issue of recycling and how to handle waste quantities of the future is a problem area that has been brought to light over the last few years and that is increasingly seeking the attention from the manufacturers and media.

Examining the waste volumes from EoL blades, these can be divided into three areas: EoL waste (decommissioned blades), manufacturing waste (in-process waste, as well as defective blades and blades used for testing) and service waste (from repairs and blade upgrading) $[20,21]$. By determining the amount of waste in $w t \%$ (percentage by total mass) from the individual categories, it is possible to estimate a total future annual amount of waste from wind turbine blades. Based on a study prepared by [13], a median for the amount of composite material used per MV installed wind turbine was determined. The study was based on 14 different wind turbine manufacturers and their 
amount of composite per MV. The result indicated that somewhere between 8 and 13.4 tons of composite material would be used per installed MV wind turbine, which compares well with other studies [13,15,22]. According to [23], they expect the blade mass per unit rated power to be between 12 and 15 tons/MW, with [22] estimating it to be 10 tons/MW. This means that, assuming an average wind turbine has a service life of 20-25 years and that the blades contain 10-13 tons/MW composite material, based on the specific number of installed MW wind turbines in Europe, there will have to be handled/recycled about 160.000 tones/year of composite waste from the year 2030 in Europe. The amount of waste will only increase year after year. The issue of handling and whether it is possible to establish an advantageous recycling method for EoL wind turbine blades is something that needs to be elucidated and explored in the near future. This study attempts to answer and elucidate the existing solutions and those that are upcoming for the recycling of EoL wind turbine blades. Moreover, the study approaches this apparent challenge using a multidisciplinary framework involving cost, environmental impact, technological maturity and the usability of the output product. Few, if any, studies have adequately performed such holistic analysis, which is why the synthesis of multiple disciplines aims at revealing a holistic benchmark of the most debated recycling methods. The study builds on a quantitatively and comprehensively comparative basis of the various recycling methods, as well as an insight and attempt to establish alternative recycling areas. The study is based on the current possibilities and their current technology readiness level (TRL) from which a comparison basis is established for the determination of the most optimal recycling.

\section{Materials and Methods}

This holistic review of recycling methods for end-of-life wind turbine blades is based on a literature review following the principles of [24], which dictates a funnel approach to conduct literature reviews by continuously filtering papers and finalizing once no further insight is obtained in the search. Most of the external literature is gained through Scopus, ScienceDirect, ResearchGate and AU Library. In the search of literature to answer the research question and sub-questions, the snowballing effect was used. This method uses the literature references and citation lists from which new articles and journals are found and reviewed. Based on selected keywords, a few introductory articles are picked, forming the base for the snowballing effect [25]. The approach with the snowballing effect is used as an introduction for each of the research sub-questions, whereby a series of search attempts have been conducted to find enough literature.

Throughout the literature review, the aim is not to use papers or documents older than 10 years. However, certain exceptions may arise if these are old theories or areas where there has been no development over the last few years. After selecting material based on the literature searches, sorting of the literature can start by start reading the abstract. The literature is then divided into categories, and careful reading is performed. In this way, it can be detected if there are missing topics or areas that can subsequently be found through new literature searches.

\section{Current Recycling Methods}

This analysis conducted in this study elaborate on the most recognized and currently most discussed recycling options when it comes to EoL WTB waste, which was discovered through the extensive literature review. The section is based on Figure 2, a diagram that describes the different methods divided into three categories: mechanical, thermal and chemical. This ends with an overview of the different methods based on their technology readiness level (TRL) as well as the expectations of the processed methods. The TRL and the usability of Fluidized Bed and High Voltage Pulse Fragmentation, respectively, are currently so low that these will not be described in more depth in this paper. However, both methods will be reflected in the common comparisons between the methods which will be presented later. 


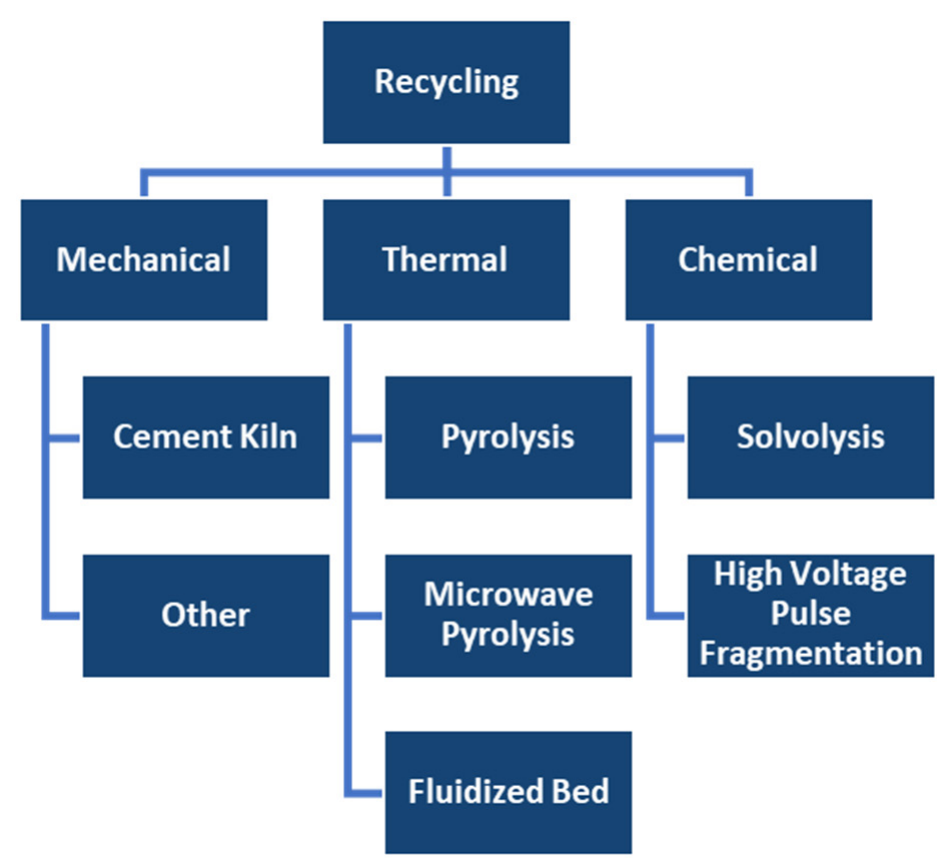

Figure 2. Possible recycling methods for EoL WTB waste.

\section{Analyzing and Benchmarking the End-of-Life Methodologies}

Work needs to be done on the basis of the European Union Waste Directive-2008/98/EC [26]. The directive divides the waste management into six areas in which prevention and reuse are classified as the best ways to solve the future problem of waste management. Disposal is considered to be the poorest method in which neither material nor energy recycling of the waste materials are used [27]. Due to the characteristic design of the wind turbine blades, the reusability options are limited, which puts greater pressure on the establishment of valuable recycling methods $[28,29]$. In the following sections, the current recycling methods for handling EoL blades will be described and compared against each other to determine which method is considered most advantageous at the present time. Recent research as well as the urge for explanation and transparency of the issue has led to the publication of Wind Europe and ETIP Winds assessments, recommendations and conclusions on the subject $[1,30]$. These publications, as well as the perspectives and conclusions from others [26,27,31,32], help to form the evaluation of each individual process method as well as its score in relation to waste management and the predicted needed investment in order to reach commercialization.

\subsection{Mechanical Recycling}

The first recycling method utilizes mechanical shredders to divide the composite material into smaller parts and pieces. According to [33], depending on the end product, various machines such as shredders, crushers, mills or grinders can be used [33]. The output of mechanical recycling can be used, among other options, as fillers, reinforcements or as raw material to produce new plastic products or for the production of cement [34], which means that the output can be divided into two categories: utilization of materials and co-processing. Here, a distinction is made between whether the residual product, after being processed, is used for the creation of new products (utilization of materials) or as a substitute for new raw materials for the production of new material (co-processing) [35]. During the co-processing phase, it will be possible both to benefit from energy recovery and material recovery. With regard to the handling of EoL WTBs, according to [36], coprocessing will benefit from the fact that the residual material (composite regrind) will be able to replace new raw materials (material recovery) through the inorganic materials, while contributing to the incineration and thus reducing the use of fossil fuels such as coal or gas (energy recovery) through the organic materials. A collaboration between the 
German cement factory Holcim and the Danish fiber composite manufacturer Fiberline has announced that 1000 tons of the composite waste from Fiberline's production can substitute/replace 150 tonnes of alumina, 200 tonnes of sand, 200 tonnes of limestone and 450 tonnes of coal in the manufacturing process of cement [37]. The collaboration between the two companies thus helps to ensure environmentally disposal/recycling of Fiberline's waste materials, while at the same time substituting and removing the use of clean new materials for the production of cement. Both companies thus achieve a better environmental assessment in their production and help to protect the environment. Studies suggest that the cement industry will be able to substitute $10 \%$ raw materials with WTG blade waste and still achieve the same properties for their end product. The problem of replacing raw materials with more blade waste is due to the presence of boron in the composites, which slows cure time of the cement [38,39]. The options are many for use of shredded composite waste from EoL blades in the form of filling material. A study was made on whether the possibilities of incorporating the use of shredded waste into the production of new thermoset polymer composites [40]. The purpose of the study was to test whether the mechanical properties of the recycled composite material had changed due to the mechanical shredding and thus investigate whether the residual product from the mechanical recycling method could be used as reinforcement for new thermoset plastic composites. The test results were found to be below theoretical values, which meant that the mechanical properties of the waste composites deteriorated drastically when exposed to the mechanical recycling method [40].

\subsection{Thermal Recycling}

The thermal recycling methodologies are mainly divided into two groups, (a) pyrolysis and (b) microwave pyrolysis. Pyrolysis is characterized by heating the material desired to be separated without the absence of oxygen under controlled conditions [6,41-43]. The process itself aims to break down the organic materials (resin) into lower weight molecules, which mainly produce gases and oil fractions that can be used for energy recovery for the pyrolysis process and other processes [41]. The inorganic material (fibers and filler materials) are left intact for recovery [33]. The pyrolysis process operates at a temperature range of about $450-700{ }^{\circ} \mathrm{C}$ depending on the type of resin used to produce the composite material. Polyester resin decomposes at temperatures between 400 and $450{ }^{\circ} \mathrm{C}$, whereas epoxy resin decomposes at higher temperatures between 500 and $550{ }^{\circ} \mathrm{C}$ [42,44]. According to Yang et al. (2011), the higher the operating temperature, the greater the degradation of the fibers will be, ultimately providing the residual material with poorer properties than the original, reducing the demand of the residual material and thus making it more difficult to compete with virgin fiber materials [45]. According to Job et al. (2016), pyrolysis at temperatures between 500 and $550{ }^{\circ} \mathrm{C}$ is considered to be the maximum for the separation and recycling of carbon fibers if the residual fibers are to maintain acceptable strength. Looking at the recycling of GF, these will lose about $50 \%$ of their material properties in pyrolysis with a temperature of $450^{\circ} \mathrm{C}$ [46]. Thus, pyrolysis is better suited for the recycling of $\mathrm{CF}$, as these are more resistant to high temperatures, making the method less attractive compared to the recycling of EoL WTBs [42]. Since EoL WTBs mainly contain GF and epoxy resin, temperature above $500-550{ }^{\circ} \mathrm{C}$ will be required to decompose the epoxy, resulting in residual GFs with more than $50 \%$ weakened material properties compared to virgin fibers.

Microwave pyrolysis is very similar to conventional pyrolysis as described above. The difference between these two pyrolysis forms lies in the name: microwave pyrolysis. In this method, microwaves are used to heat the waste material, whereby the organic material is decomposed into low molecular weight substances and the inorganic materials remain. The microwave pyrolysis is carried out in a nitrogen atmosphere chamber and is carried out at temperatures between 300 and $600{ }^{\circ} \mathrm{C}$ [47]. In order to ensure that all epoxy is decomposed, the method needs to be carried out in the top of its temperature range, since epoxy decomposes at a temperature range of $500-550{ }^{\circ} \mathrm{C}$, as mentioned earlier. The advantage of heating with microwave radiations is that the bulk of the material is 
heated throughout and at the same temperature. Since polymers usually have low thermal conductivity, the use of microwaves means that the temperature during the process can be kept lower than in normal pyrolysis in which the waste material is heated by convection. The lower temperature ensures minimal thermal degradation of the glass fibers, which improves the mechanical properties of the recycled fiber materials [44].

\subsection{Chemical Recycling}

Chemical recycling, with the most common method being solvolysis, is a method that utilizes a solvent composed of catalysts/additives to depolymerize the chemical crosslinked bond present in thermoset polymer products. The solvents may be, for example, alcohols, water, glycols or ketones [45]. The reactive solvent will, in combination with temperature and pressure, diffuse into the composite material and break specific bonds in the resin, which abolishes the cross-binding between resin and fibers. In this way, it is possible to recover not only the fibers but monomers from the resin, as well [48]. The method can be used for both separations of GF and CF.

Problems also lie in the separation of GF, as these lose a lot of their material properties when extracted at high temperatures. In order to separate the GF without losing a lot of the properties, a method using low temperature and pressure is applied, whereby the recovered fibers will keep more of their properties and make the residual product more valuable [42]. This means that solvolysis can be divided into two categories depending on temperature and pressure:

- $\quad$ high temperature $\left(>200^{\circ} \mathrm{C}\right)$ and pressure (HTP)

- $\quad$ low temperature $\left(<200^{\circ} \mathrm{C}\right)$ and pressure (LTP)

HTP is the most environmentally friendly of the two types. This method uses mostly water or alcohol as its solvent. The LTP method uses more aggressive solvents, making it less environmentally friendly than the HTP method. The advantageous of the LTP is that the operating temperature and pressure are kept relatively low (normally atmospheric conditions and under $200^{\circ} \mathrm{C}$ ), which secures most of the material properties of the residual fibers.

The problem with the solvolysis process lies in the fact that the choice of solvent, temperature and pressure differs depending on how the composite material is constructed. For example, higher temperatures and pressures must be used for components made of epoxy resin rather than if they are made of polyester resin fabric. According to [30], the chemical methods are considered to be more dangerous compared to mechanical and thermal recycling, as potentially hazardous substances are being used that could harm the environment, as well as the process, take places under extremely hazardous conditions, high temperatures and possibly high pressure [32]. These reasons make it difficult to create an industrial-level chemical FRP waste recycling site because it is an expensive and technologically complex process.

\subsection{A Comparative Analysis of the Recycling Methodologies}

Based on the established knowledge about the use of the individual recycling methods and their historical and current developments as well as the conditions and requirements for each method, it is possible to give an estimate of the methods and their technologybased on what is called a technology readiness level. Technology readiness level (TRL) is a framework to estimate and evaluate a specific technology's maturity, which is ranked by a score from 1 to 9 .

- TRL 1-4: Lab Scale

- TRL 5-7: Pilot Scale

- TRL 8-9: Commercial scale

Combining the TRL scale with the knowledge about the different recycling methods' locations in the European waste hierarchy and the possible residual material outcomes, it is possible to place the methods in Table 1 as an overview and in Figure 3 as a TRL 
diagram overview. The different scores are evaluated based on comparisons between other research $[26,27,31,49,50]$, the rating from the European waste hierarchy and through communication with the affected industries. The waste management score is categorized into three groups, low, middle and high, which is based on the properties of the various processes, output and TRL but, in particular, on the residual material value, which will be described more Section 4.1. These costs are also indicated and evaluated in the papers from Europe Wind and EtipWind [1,30]. The individual score is indicative and varies among EU recyclers using the same recycling method due to varying processing parameters, capacity and throughput.

Table 1. Overview of the current recycling methods (Reproduced from: $[26,27,31,49,50])$.

\begin{tabular}{|c|c|c|c|c|c|c|c|}
\hline $\begin{array}{l}\text { RECYCLING } \\
\text { METHOD }\end{array}$ & MECHANICAL & $\begin{array}{c}\text { CO- } \\
\text { PROCESSING }\end{array}$ & Pyrolysis & $\begin{array}{l}\text { MICROWAVE } \\
\text { PYROLYSIS }\end{array}$ & $\begin{array}{c}\text { FLUIDIZED } \\
\text { BED }\end{array}$ & SOLVOLYSIS & HVPF \\
\hline TRL score & 9 & $8-9$ & 7 & 4 & $4 / 5$ & $5 / 6$ & 5 \\
\hline $\begin{array}{l}\text { Waste } \\
\text { management } \\
\text { score }\end{array}$ & Low & Middle & High & Middle/High & Middle/High & High & Middle \\
\hline $\begin{array}{l}\text { Predicted } \\
\text { needed } \\
\text { investment }\end{array}$ & Low & Low/Middle & Low/Middle & High & Middle & High & High \\
\hline $\begin{array}{l}\text { Machining } \\
\text { options }\end{array}$ & $\mathrm{GF}+\mathrm{CF}$ & GF & $\mathrm{CF}+\mathrm{GF}$ & $\mathrm{CF}+\mathrm{GF}$ & $\mathrm{CF}+\mathrm{GF}$ & $\mathrm{CF}+\mathrm{GF}$ & $\mathrm{CF}+\mathrm{GF}$ \\
\hline
\end{tabular}

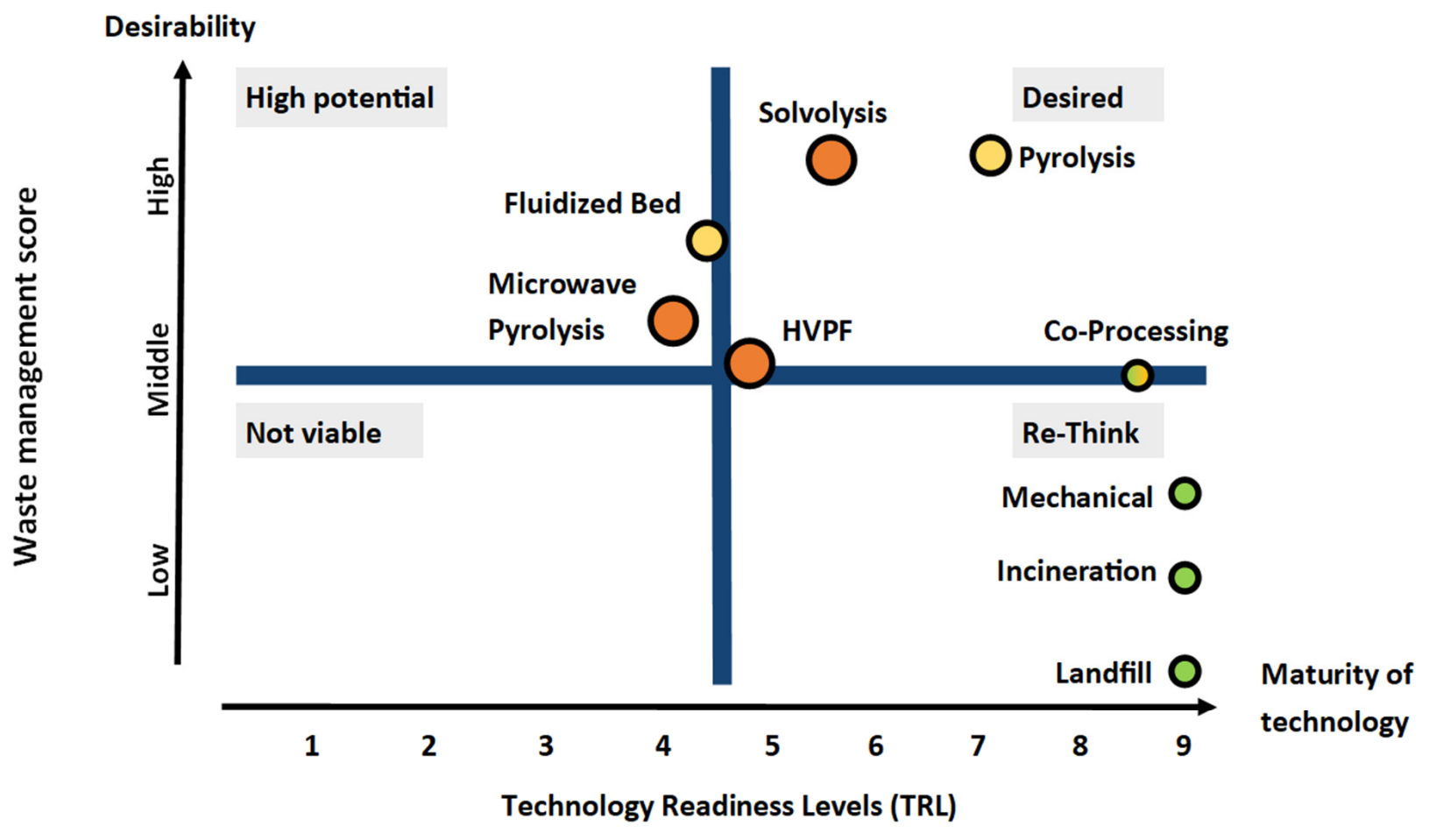

Predicted needed investment for

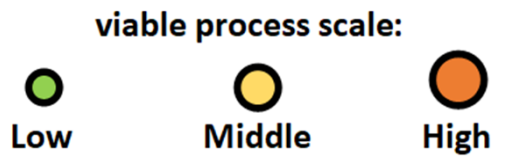

Figure 3. TRL of the different recycling methods.

Based on the overview of the different methods and their current TRL, the mechanical recycling method used to enable co-processing is currently indicated as the most advantageous way of handling EoL blade waste, as this method is capable of operating at a 
commercial scale. The next step will be to investigate the applicability of the methods in relation to material composition and residual materials and comparing the processing costs against the prices for new fiber materials.

\section{Processing Cost and Predicted Material Outputs}

In order to investigate and compare the different waste handling methods, it is necessary to know their processing costs and the potential outcome of the residue materials. Generally, it is estimated to require $111.88 \mathrm{MJ} / \mathrm{kg}$ to produce composite material. This number includes fiber production, fabric production, resin production, the pultrusion process and the additives in the materials [51]. According to a study made by [52], it is concluded that it only takes a tenth of the energy to recover the materials through recycling compared to virgin materials. This result is acknowledged by [44], which means that the recycling energy demand is comparatively lower (10 to 20 times lower) compared to the energy demand for new materials. They state that the energy demand for producing virgin GF is $13-32 \mathrm{MJ} / \mathrm{kg}$, whereas CF uses $183-286 \mathrm{MJ} / \mathrm{kg}$. Based on these values and the operating values for the different recycling/recovery methods found in [44,52-55], it is possible to compare the usability hereof (see Figure 4).

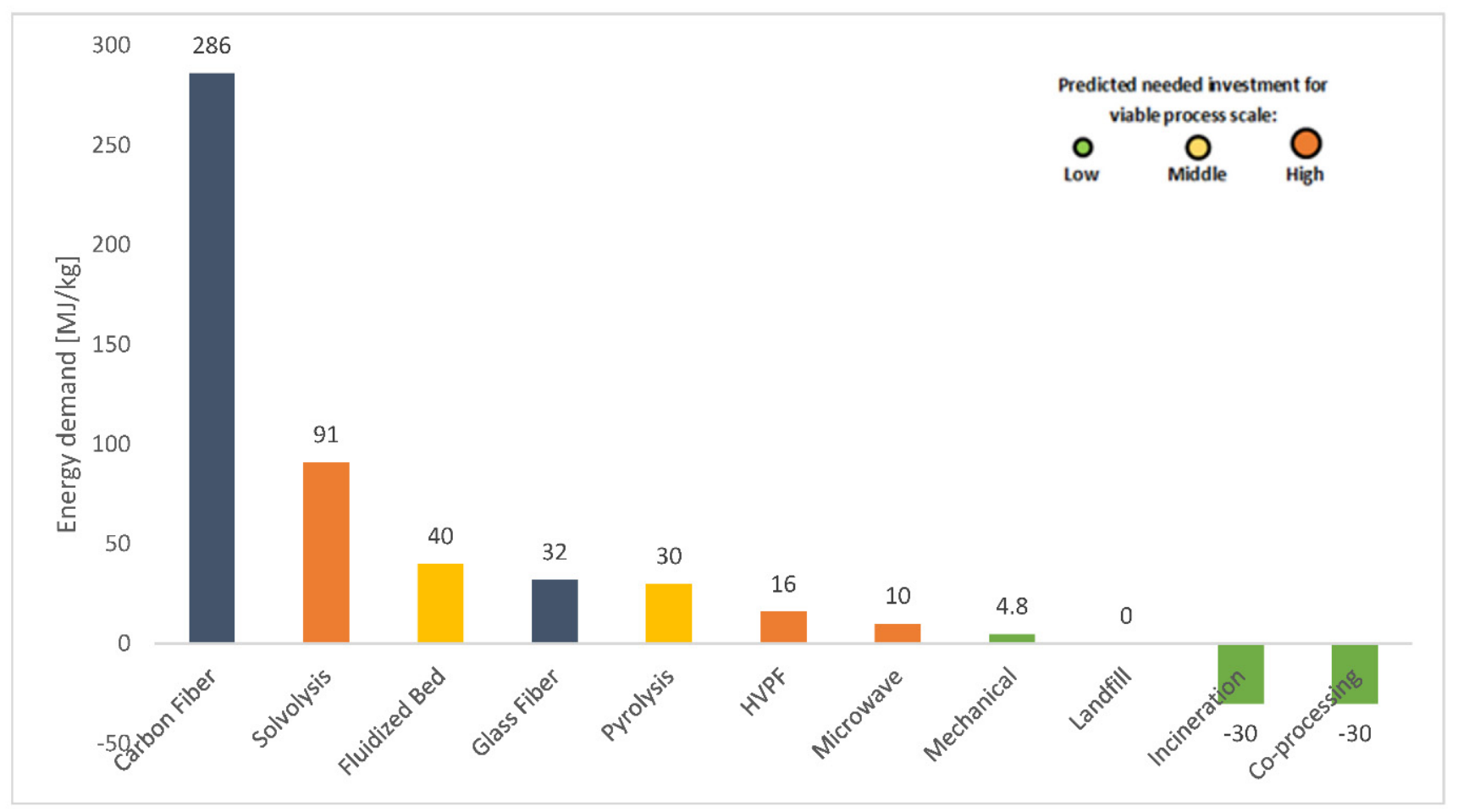

Figure 4. Energy demand for the different methods and for producing virgin fibers.

Figure 4 shows a comparison of the different recycling/recovery methods and what their individual processing energy demand is. Currently, most of the methods rely on using the mechanical method as an initial step to reduce the size of the waste materials into manageable sizes. The diagram in Figure 4 only shows the processing energy demand for the current method, which means that no pre-processing or other energy-intensive operations are added. Therefore, the energy demand is only for processing the chosen recycling method. Based on Figure 4, some of the recycling methods indicate being more suitable for one type of fiber material that others. An example could be the chemical recycling method (solvolysis), which has a processing energy demand between 21 and $91 \mathrm{MJ} / \mathrm{kg}$ compared to the energy demand required to produce virgin GF (13-32 MJ $/ \mathrm{kg}$ ); it most likely exceeds this demand, thus making it unprofitable to use for recycling GF. This assumption is only based on the energy demand required for the processing of the 
recycling method. Another way of comparing the methods is by looking at the retained strength of the fibers during the different processing.

\subsection{A Comparative Analysis of the Remaining Strength and Values of the Recycled Fibers}

The retained strengths can be seen in Table 2, where it shows the retained strength compared to virgin fibers. Due to different lengths and amount of resin residue on the fibers after processing, the fibers require post-processing to get as clean and homogeneous as virgin fibers. Currently, there is still limited data available about the post-processing demand [55], which means a 10\% reduction in the retained strength to take this postprocessing operation into consideration.

Table 2. Retained tensile strength from the different EoL options compared to virgin fibers. (Inspired by [55]).

\begin{tabular}{ccccccc}
\hline Method & Mechanical & Pyrolysis & $\begin{array}{c}\text { Microwave } \\
\text { Pyrolysis }\end{array}$ & $\begin{array}{c}\text { Fluidized } \\
\text { Bed }\end{array}$ & Solvolysis & HVPF \\
\hline $\begin{array}{c}\text { Glass Fiber } \\
\text { Carbon }\end{array}$ & $78 \%$ & $52 \%$ & $52 \%$ & $50 \%$ & $58 \%$ & $88 \%$ \\
Fiber & $50 \%$ & $78 \%$ & $80 \%$ & $75 \%$ & $95 \%$ & $83 \%$ \\
\hline
\end{tabular}

Combining Figure 4 with the results from Table 2 illustrates which fiber materials the different EoL methods are best capable of handling due to energy demand and the outcome of the residue fibers. As previously mentioned, many of the current recycling methods are still running on a pilot or lab scale. This means small sample sizes, and this often requires the use of mechanical shredding or other size reducing, which will have an impact on the overall retained strength of the residue material. From Figure 4 and Table 2, together with the research from $[25,26,47]$, an estimated process cost and residue material value diagram is created (see Figure 5).

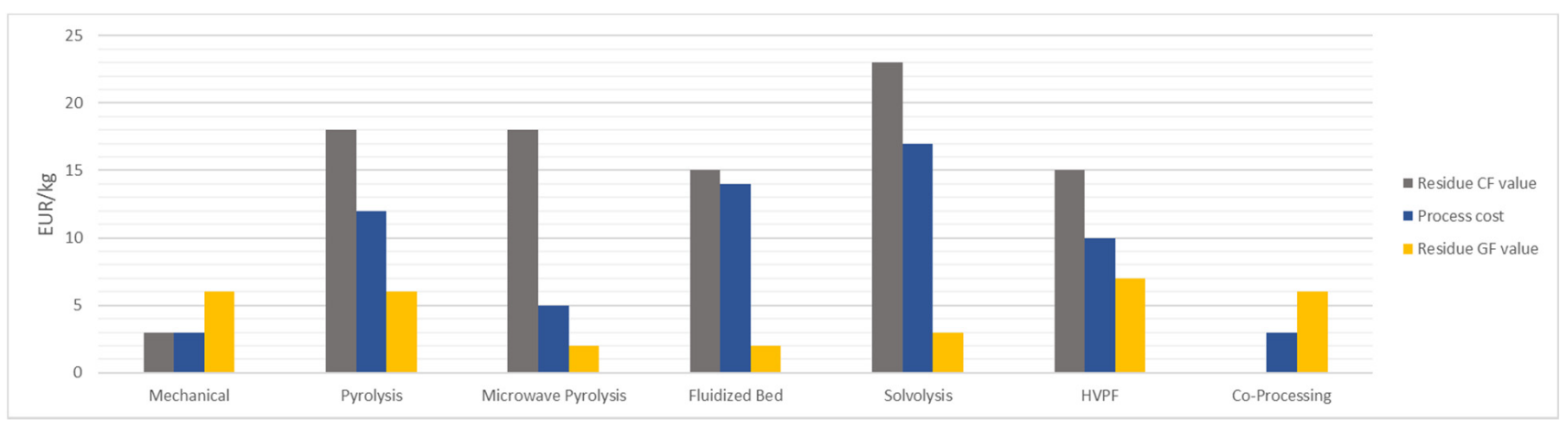

Figure 5. Estimated process-related costs and residue material value. (Based on Figure 4, Tables 1 and 2 and [30,56]).

Figure 5 provides a visual understanding of the connection between processing cost and the value of the residue material. The different sizes of the bars are only an indication, while it can vary among different recycling plants due to parameters such as throughput capacity, temperature/pressure and processing time. The fact that almost no two WTBs are alike also means that this can affect the process cost and the value of the residue material after being recycled. Figure 5 outlines that, currently, the most suitable recycling method for GF is through the mechanical method and preferably as a co-processing material for the cement production. The other processes by which the fiber materials can be recovered are still too costly in terms of the process. These methods rely more on CF materials, as these are far more expensive to produce than GF. Combining all this, it is indicated that no industrialized viable recycling technology is profitable yet, which may be due to a lack of value and material streams that must back up the most mature technologies to accommodate the implementation of a recycling technology/strategy. The lack of usability and thus financial gain also lies in the method's need for shortening or granulated 
composite pieces, which gives short residue fibers that are not applicable to produce, for example, new WTBs. The demand for methods that can handle and generate continuous fibers is therefore important in relation to the establishment of an economic benefit of the recycling methods.

\subsection{Choosing the Right Recycling Method}

Based on the knowledge gathered as well as the characteristics and possibilities of the individual recycling methods, a spider web has been prepared for the selection of the best solution. The choosing is based on factors: environmental score, technology readiness level (TRL), economic feasibility and usability of residual fibers. The higher the individual methods score for the different factors, the better the degree of application of the specific type of fiber material. The input on the TRL is directly implemented from Table 1; meanwhile, the other three factors have been weighted in a score from 0 to 10 , which is based on the summarized literature review on the respective topics. The economic feasibility and the usability of the residual fibers is based on the literature review, along with the scores, inputs and conclusions described in Figure 5 and Table 2, where the environmental score is based on reviews + Figure 4. Again, the individual scores is indicative and varies among EU recyclers using the same recycling method due to varying processing parameters, capacity and throughput. The recycling methods are categorized according to their use in the handling of fiberglass and carbon fiber. As mentioned earlier, the use of fiberglass is to be commercialized with great care in order to handle the quantities of waste that already exist and are expected to come in the near future from EoL WTBs.

Based on the fiberglass waste (GF), it is clearly seen in Figure 6 that co-processing has the greatest potential based on the score in TRL, environment and economy. The method leaves no residual fibers, which gives it a minimal score in this factor; however, none of the competing recycling methods can provide competitive residual fibers and, therefore, cannot overshadow the other properties of the co-processing method. As described earlier, the spiderweb clearly visualizes how the co-processing method for handling EoL WTB waste is clearly regarded as the most advantageous recycling method at this time. With the future prospects for the implementation and greater use of carbon fiber (CF) for the production of new wind turbine blades, in the future, larger and larger quantities of CF waste will have to be handled and reused. The existing recycling methods such as pyrolysis and solvolysis will be the methods most likely to establish a commercialized recycling route for this type of waste. This is also seen in the spider web where pyrolysis is the one of the methods that scored the highest in the handling of CF waste. If a future solution is to be established whereby minimal residual waste is created, a combined solution between co-processing and pyrolysis could be the solution. By sorting the CFs from the involved blades, this material can be recycled through pyrolysis, whereby minimal residual waste will occur. The remaining waste from blades will be able to substitute raw materials and fuel for cement production. In this way, the co-processing method will ensure that no residual waste is generated and thus help to ensure a greener and more advantageous handling of the EoL WTB waste. By creating a commercially and economically neutral or profitable recycling method, wind turbine OEMs and their customers will ensure an environmental improvement of the existing handling that takes place through landfills. Several studies show the strongly negative environmental impact that can occur through landfills, where urban and special wastes are disposed of both legally and illegally and, thus, many pollutants, both inorganic and organic, are released into the ground $[57,58]$. By finding a solution, the wind turbine industry will be one step closer to achieving the environmental assessment associated with renewable energy. 


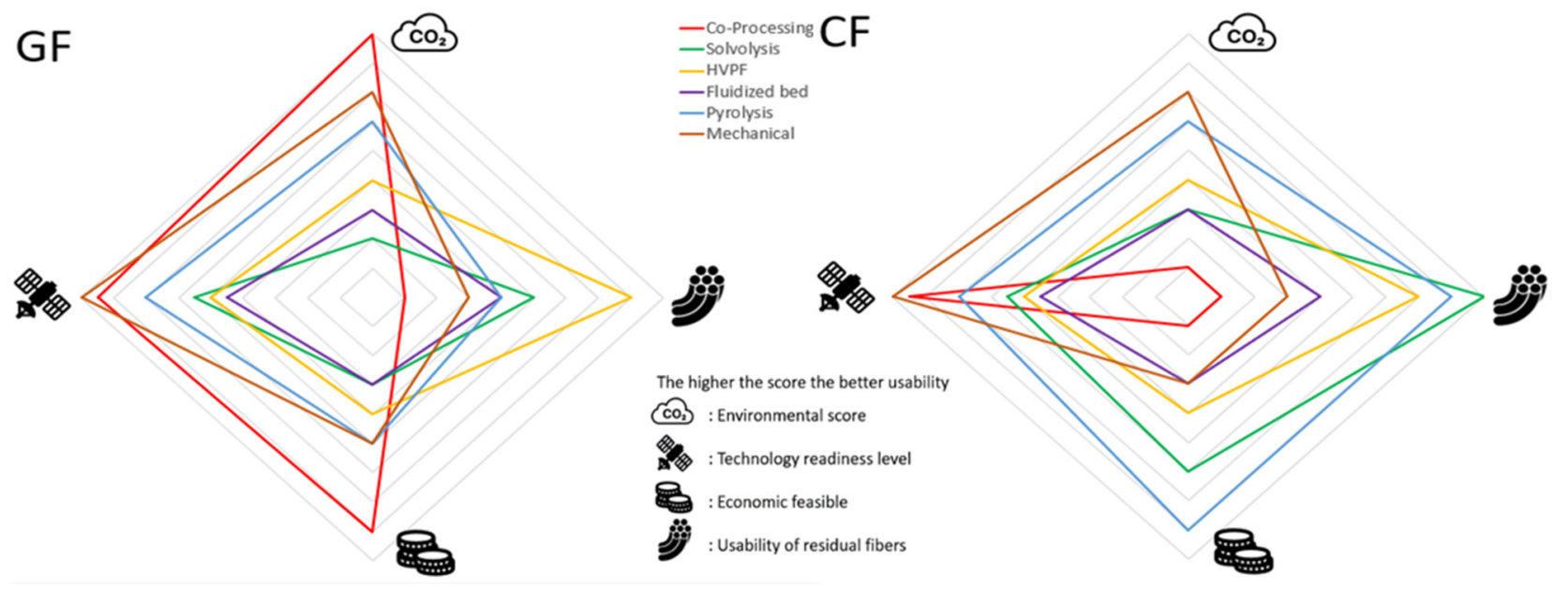

Figure 6. Spider web comparison of the possible recycling methods.

\section{Conclusions}

This research identified recycling through co-processing to produce cement as the most suitable method for handling EoL WTBs based on the current TRL of the various recycling methods. The review carried out in this study discovered no alternative method that could use the WTB waste for recycling or substitution. Co-processing through cement production is recognized by the European Commission as being recycling, which means that this method could lead Vestas and the rest of the wind turbine OEMs' assessments of WTBs to be based on the linear economic mindset to move toward a reuse or circular economic mindset. Based on the Swiss multinational cement group Holcim, the implementation and substitution of EoL WTB waste for the production of cement could reduce up to $16 \%$ of their $\mathrm{CO}_{2}$ footprint [36]. The use of EoL WTB waste for the production of cement will benefit both the environmental assessment of the mills and the cement plants. Therefore, coprocessing is the most applicable, environmentally friendly and economically appropriate recycling method for handling the present and future waste from EoL WTBs.

Author Contributions: Conceptualization, E.B.P. and P.E.; methodology, E.B.P.; formal analysis, E.B.P.; writing-original draft preparation, E.B.P.; writing-review and editing, P.E.; visualization, E.B.P.; supervision, P.E. All authors have read and agreed to the published version of the manuscript.

Funding: This research received no external funding.

Institutional Review Board Statement: Not applicable.

Informed Consent Statement: Not applicable.

Data Availability Statement: Not applicable.

Conflicts of Interest: The authors declare no conflict of interest.

\section{References}

1. WindEurope. Accelerating Wind Turbine Blade Circularity. Themat Reports. May 2020, pp. 11-13. Available online: https: // windeurope.org/data-and-analysis/product/accelerating-wind-turbine-blade-circularity/ (accessed on 12 July 2021).

2. WindEurope; Komusanac, I.; Fraile, D.; Brindley, G. Wind Energy in Europe in 2018 - Trends and Statistics; Wind Europe: Brussels, Belgium, 2019; p. 32.

3. Wind Europe. Wind Energy in Europe in 2019; Wind Europe: Brussels, Belgium, 2020.

4. Nghiem, A.; Fraile, D.; Mbistrova, A.T.R. Wind Energy in Europe: Outlook to 2023; Wind Europe: Brussels, Belgium, $2018 ;$ p. 44.

5. Enevoldsen, P. A socio-technical framework for examining the consequences of deforestation: A case study of wind project development in Northern Europe. Energy Policy 2018, 115, 138-147. [CrossRef]

6. Jensen, J.P. Evaluating the environmental impacts of recycling wind turbines. Wind Energy 2019, 22, 316-326. [CrossRef]

7. Sovacool, B.; Perea, M.A.M.; Matamoros, A.V.; Enevoldsen, P. Valuing the manufacturing externalities of wind energy: Assessing the environmental profit and loss of wind turbines in Northern Europe. Wind Energy 2016, 19, 1623-1647. [CrossRef] 
8. Garrett, P.; Razdan, P. Life Cycle Assessment of Electricity Production from an Onshore V90-3. 0MW Wind Plant. Vestas Wind Syst A/S Vestas. 2017, pp. 1-106. Available online: https://www.vestas.com/ \{\}/media/vestas/about/sustainability/pdfs/lca_ v903mw_version_1_1.ashx (accessed on 10 June 2021).

9. Hoefer, M.; Company, T.B. Wind Turbine Blade Recycling: An Economic Decision Framework; Iowa State Univesrity: Imes, IA, USA, 2016.

10. Andersen, P.D.; Bonou, A.; Beauson, J.; Brøndsted, P. Recycling of Wind Turbines; Technical University of Denmark: Lingby, Denmark, 2014; pp. 91-97.

11. Vestas Wind Systems A/S. Sustainability at Vestas. 2019. Available online: https://www.vestas.com/en/about/sustainability\#! (accessed on 9 September 2019).

12. Job, S. Recycling glass fibre reinforced composites-History and progress. Reinf. Plast. 2013, 57, 19-23. [CrossRef]

13. Liu, P.; Barlow, C.Y. Wind turbine blade waste in 2050. Waste Manag. 2017, 62, 229-240. [CrossRef]

14. Mishnaevsky, L.; Branner, K.; Petersen, H.N.; Beauson, J.; McGugan, M.; Sørensen, B.F. Materials for Wind Turbine Blades: An Overview. Materials 2017, 10, 1285. [CrossRef]

15. Wind Europe. Discussion Paper on Managing Composite Blade Waste; Wind Europe: Brussels, Belgium, 2017 ; Volume 39, p. 18.

16. Schubel, P.J.; Crossley, R.J. Wind Turbine Blade Design review. Wind Eng. 2012, 36, 365-388. Available online: www.nrel.gov/ publications (accessed on 10 June 2021). [CrossRef]

17. Brøndsted, P.; Nijssen, R.P.L. Advances in Wind Turbine Blade Design and Materials; Elsevier: Amsterdam, The Netherlands, 2013; p. 484.

18. Cousins, D.S.; Suzuki, Y.; Murray, R.; Samaniuk, J.R.; Stebner, A.P. Recycling glass fiber thermoplastic composites from wind turbine blades. J. Clean. Prod. 2019, 209, 1252-1263. [CrossRef]

19. Liu, P.; Barlow, C.Y. The Environmental Impact of Wind Turbine Blades the Environmental Impact of Wind Turbine Blades; IOP Publishing Ltd.: Bristol, UK, 2016.

20. Correia, J.R.; Almeida, N.; Figueira, J.R. Recycling of FRP composites: Reusing fine GFRP waste in concrete mixtures. J. Clean. Prod. 2011, 19, 1745-1753. [CrossRef]

21. Liu, P.; Barlow, C. An update for wind turbine blade waste inventory. In Proceedings of the EWEA Annual Conference, Copenhagen, Denmark, 10-12 March 2015.

22. Albers, H. Recycling of Wind Turbine Rotor Blades-Fact or Fiction? DEWI Mag. 2009, 34, 32-41.

23. Nghiem, A.; Pineda, I. Wind Energy in Europe: Scenarios for 2030; Wind Europe: Brussel, Belgium, 2017; p. 32. Available online: https:/ / windeurope.org/wp-content/uploads / files/about-wind/reports/Wind-energy-in-Europe-Scenarios-for-20 30.pdf\%0Ahttp:/ / www.ewea.org/fileadmin/files/library / publications/reports/EWEA-Wind-energy-scenarios-2030.pdf (accessed on 10 June 2021).

24. Enevoldsen, P. Onshore wind energy in Northern European forests: Reviewing the risks. Renew. Sustain. Energy Rev. 2016, 60, 1251-1262. [CrossRef]

25. Wohlin, C. Guidelines for snowballing in systematic literature studies and a replication in software engineering. In Proceedings of the 18th International Conference on Evaluation and ASSESSMENT in software Engineering, London, UK, 13-14 May 2014.

26. European Comission Directive 2008/98/EC on Waste (Waste Framework Directive). Available online: https: / / ec.europa.eu/ environment/waste/framework/ (accessed on 15 October 2020).

27. Devic, A.-C.; Ierides, M.; Fernandez, V.; Verbenkov, M.; Bax, L. Polymer Composites Circularity. Suschem 2018. Available online: https:/ / baxcompany.com/wp-content/uploads/2018/11/Suschem_composites_circularity_pages.pdf (accessed on 12 July 2021).

28. Gharfalkar, M.; Court, R.; Campbell, C.; Ali, Z.; Hillier, G. Analysis of waste hierarchy in the European waste directive 2008/98/EC. Waste Manag. 2015, 39, 305-313. [CrossRef] [PubMed]

29. Romain, S. Dissection of Wind Turbine Blades for the GENVIND Project IState of Green. 2013. Available online: https: //stateofgreen.com/en/partners/state-of-green/news/dissection-of-wind-turbine-blades-for-the-genvind-project/ (accessed on 23 September 2019).

30. ETIP Wind. How Wind is Going Circular_Blade Recycling; Europan Union: Brussels, Belgium, 2019.

31. Rybicka, J.; Tiwari, A.; Leeke, G. Technology readiness level assessment of composites recycling technologies. J. Clean. Prod. 2016, 112, 1001-1012. [CrossRef]

32. Delvere, I.; Iltina, M.; Shanbayev, M.; Abildayeva, A.; Kuzhamberdieva, S.; Blumberga, D. Evaluation of Polymer Matrix Composite Waste Recycling Methods. Environ. Clim. Technol. 2019, 23, 168-187. [CrossRef]

33. Cherrington, R.; Goodship, V.; Meredith, J.; Wood, B.; Coles, S.; Vuillaume, A.; Feito-Boirac, A.; Spee, F.; Kirwan, K. Producer responsibility: Defining the incentive for recycling composite wind turbine blades in Europe. Energy Policy 2012, 47, 13-21. [CrossRef]

34. Chen, J.; Wang, J.; Ni, A. Recycling and reuse of composite materials for wind turbine blades: An overview. J. Reinf. Plast. Compos. 2019, 38, 567-577. [CrossRef]

35. Vladimirov, V.; Bica, I. Mechanical recycling: Solutions for glass fibre reinforced composites. In Proceedings of the International Symposium "The Environment and the Industry", Bucharest, Romania, 28-29 September 2017; pp. 159-165. [CrossRef]

36. Aliancys Europe. Let's Talk Recycling-Renewable Value from Composites; Bax and Company: Barselona, Spain, 2016.

37. Fiberline Composites. Recycling. 2019. Available online: https:// fiberline.com/recycling (accessed on 3 October 2019). 
38. Fonte, R.; Xydis, G. Wind turbine blade recycling: An evaluation of the European market potential for recycled composite materials. J. Environ. Manag. 2021, 287, 112269. [CrossRef]

39. Nagle, A.J.; Delaney, E.L.; Bank, L.C.; Leahy, P.G. A Comparative Life Cycle Assessment between landfilling and Co-Processing of waste from decommissioned Irish wind turbine blades. J. Clean. Prod. 2020, 277. [CrossRef]

40. Beauson, J.; Madsen, B.; Toncelli, C.; Brøndsted, P.; Bech, J.I. Recycling of shredded composites from wind turbine blades in new thermoset polymer composites. Compos. Part A Appl. Sci. Manuf. 2016, 90, 390-399. [CrossRef]

41. Ramirez-Tejeda, K.; Turcotte, D.A.; Pike, S. Unsustainable wind turbine blade disposal practices in the united states: A case for policy intervention and technological innovation. New Solut. 2017, 26, 581-598. [CrossRef]

42. Oliveux, G.; Dandy, L.O.; Leeke, G. Current status of recycling of fibre reinforced polymers: Review of technologies, reuse and resulting properties. Prog. Mater. Sci. 2015, 72, 61-99. [CrossRef]

43. Overcash, M.; Twomey, J.; Asmatulu, E.; Vozzola, E.; Griffing, E. Thermoset composite recycling-Driving forces, development, and evolution of new opportunities. J. Compos. Mater. 2017, 52, 1033-1043. [CrossRef]

44. Job, S.; Leeke, G.A.; Mativenga, P.T.; Oliveux, G.; Pickering, S.J.; Shuaib, N.A. Composites Recycling: Where Are We Now? 2016. Available online: https://compositesuk.co.uk/system/files/documents/Recycling\%20Report\%202016.pdf (accessed on 12 July 2021).

45. Yang, Y.; Boom, R.; Irion, B.; van Heerden, D.-J.; Kuiper, P.; de Wit, H. Recycling of composite materials. Chem. Eng. Process. Process. Intensif. 2012, 51, 53-68. [CrossRef]

46. Pickering, S.J.; Kelly, R.M.; Kennerley, J.R.; Rudd, C.D.; Fenwick, N.J. A fluidised-bed process for the recovery of glass fibres from scrap thermoset composites. Compos. Sci. Technol. 2000, 60, 509-523. [CrossRef]

47. Åkesson, D.; Foltynowicz, Z.; Christéen, J.; Skrifvars, M. Microwave pyrolysis as a method of recycling glass fibre from used blades of wind turbines. J. Reinf. Plast. Compos. 2012, 31, 1136-1142. [CrossRef]

48. Gleitsmann, C. Economic viability and Environmental Assessment of Disposal Methods for Wind Turbine Blades. Master's Thesis, University of Southern Denmark, Esbjerg, Denmark, 2016.

49. Van Oudheusden, A. Recycling of Composite Materials; Delft University of Technology: Delft, The Netherlands, 2016.

50. Halliwell, S. End of Life Options for Composite Waste Recycle. Natl. Compos. Netw. 2006, 1-41. Available online: https: / / compositesuk.co.uk/system/files/documents/endoflifeoptions.pdf (accessed on 10 June 2021).

51. Song, Y.S.; Youn, J.R.; Gutowski, T.G. Life cycle energy analysis of fiber-reinforced composites. Compos. Part A Appl. Sci. Manuf. 2009, 40, 1257-1265. [CrossRef]

52. Shuaib, N.A.; Mativenga, P. Energy demand in mechanical recycling of glass fibre reinforced thermoset plastic composites. J. Clean. Prod. 2016, 120, 198-206. [CrossRef]

53. Meng, F.; McKechnie, J.; Turner, T.; Pickering, S. Energy and environmental assessment and reuse of fluidised bed recycled carbon fibres. Compos. Part A Appl. Sci. Manuf. 2017, 100, 206-214. [CrossRef]

54. Wong, K.; Rudd, C.; Pickering, S.; Liu, X.L. Composites recycling solutions for the aviation industry. Sci. China Technol. Sci. 2017, 60, 1291-1300. [CrossRef]

55. Liu, P.; Meng, F.; Barlow, C.Y. Wind turbine blade end-of-life options: An eco-audit comparison. J. Clean. Prod. 2019, 212, 1268-1281. [CrossRef]

56. Ierides, M.; Reiland, J.; Dierckx, A. Wind turbine blade circularity: Technologies and practices around the value chain. In Proceedings of the Wind Conference Exhibit, Bilbao, Spain, 2-4 April 2019; pp. 1-38.

57. Bortone, I.; Chianese, S.; Erto, A.; Di Nardo, A.; De Crescenzo, C.; Karatza, D.; Santonastaso, G.; Musmarra, D. An optimized configuration of adsorptive wells for the remediation of an aquifer contaminated by multiple aromatic hydrocarbon pollutants. Sci. Total. Environ. 2019, 696, 133731. [CrossRef]

58. He, L.; Shao, F.; Ren, L. Sustainability appraisal of desired contaminated groundwater remediation strategies: An informationentropy-based stochastic multi-criteria preference model. Environ. Dev. Sustain. 2021, 23, 1759-1779. [CrossRef] 